http://dx.doi.org/10.5007/1980-3532.2012n7p70

\title{
Uma crítica seminal ao keynesianismo
}

José Carlos Mendonça

Doutorando em Ciências Sociais (Universidade Estadual de Campinas - UNICAMP)

Pesquisador do Laboratório de Sociologia do Trabalho (LASTRO - UFSC)

jose.carlos@ufsc.br

MATTICK, Paul. Marx e Keynes, os limites da Economia Mista. Lisboa: Antígona, 2010, 496 p.

Originais recebidos em: 10/06/2012

Aceito para publicação em: 26/06/2012

A crise no capitalismo mundial em 2008 produziu ao menos um pequeno subproduto favorável ao leitor de língua portuguesa em Portugal. Impulsionou a publicação, com 40 anos de atraso em relação ao original em inglês de 1969, de Marx e Keynes, os limites da Economia Mista (MK), obra que critica pela raiz as proposições e idéias do maior ideólogo da economia mista John Maynard Keynes (1883-1946). Terminou para os portugueses em 2010, o que para os franceses havia terminado em 1972, e para os dinamarqueses em $1973 .^{1}$

Escrita por Paul Mattick (1904-1981) - um operário alemão autodidata emigrado para os EUA - que anunciou logo na introdução que sua tese era demonstrar o caráter efêmero da solução proposta pelo keynesianismo aos problemas econômicos do mundo capitalista, bem como que as condições que possibilitavam tal eficácia passageira estavam por desaparecer. Considerando que a crítica marxiana da economia política ganhava nova importância pela "capacidade de compreender e transcender

\footnotetext{
${ }^{1}$ A menção à tradução de MK para o dinamarquês não é fortuita. Foi da Dinamarca que partiu o convite para que Mattick realizasse uma série de conferências na Universidade Roskilde, instituição em que posteriormente se tornou professor visitante no ano letivo de 1974-75.
} 
simultaneamente a 'velha' e a 'nova' economia", Mattick se propôs nesse livro a "submeter a teoria e a prática keynesianas a uma crítica marxista, e, para além disso, tentar explicar os acontecimentos e tendências políticos e econômicos com a ajuda da análise marxiana." (p. 8)

Para comprovar suas teses, Mattick estruturou MK em vinte e duas partes, mas alertou ao leitor não se tratar de um livro apresentado "na forma de uma narrativa encadeada: algumas das suas partes foram escritas em ocasiões diversas e em diferentes épocas. Mas todas elas são indispensáveis e referem-se ao tema único da economia mista e às diferenças entre Marx e Keynes.” (p. 8)

Mattick inicia por apresentar os pontos característicos da escola de economia keynesiana, que foi adjetivada de "socialista" pelos neoclássicos e de "marxismo da nossa época" por "socialistas inconsistentes" que "tentaram amalgamar Marx com Keynes" afirmando que a descrença de Marx quanto ao futuro da sociedade burguesa devia-se "a sua incapacidade ou relutância de criticar os clássicos em termos construtivos. E que Keynes concretizara as aspirações de Alfred Marshall de um capitalismo reformado e melhorado.” (p.10) No entanto, Mattick reconhece uma conexão necessária entre os dois, pois Marx antecipou a crítica de Keynes da teoria neoclássica ao criticar a teoria clássica, ambos reconheceram o dilema capitalista numa situação de baixa da taxa de formação de capital. Mas Keynes apontou a causa como carência de incentivo ao investimento, e Marx foi à raiz do dilema: "o caráter da produção enquanto produção de capital.” (p. 34).

Na concepção de Mattick, que admite muita dificuldade em considerar que as teorias de Keynes tenham revolucionado o pensamento econômico, aquelas são uma versão "moderna, repensada, e possivelmente, aperfeiçoada" (p. 21) da teoria da acumulação de Malthus (1766-1834). Mas revela que o termo revolucionário pode ser tranquilamente aplicado se for utilizado no sentido de ter produzido resultados teóricos distintos do que produzia o pensamento econômico contemporâneo à sua elaboração. Tal aparência revolucionária deveu-se ao modo como Keynes rejeitou a "lei do mercado" de J. B. Say (1767-1832) ${ }^{2}$ e não às propostas Keynesianas para suavizar os problemas da economia por meios monetários.

\footnotetext{
${ }^{2}$ Resumidamente, a lei do mercado de Say afirma que para se ter uma fundação efetiva para demanda é derivada de uma prévia fonte de oferta. Keynes interpretou que "a oferta automaticamente cria demanda". Mattick nos lembra que, para Marx, a lei de Say era absurda pela "[...] discrepância crescente entre as exigências de lucro para a expansão do capital e as exigências produtivas da sociedade [...].” (p. 34).
} 
Dialogando criticamente com autores marxistas como Paul Sweezy (1910-2004), Rudolf Hilferding (1877-1941), Karl Korsch (1886-1961), e Rosa Luxemburg (18711919), Mattick percorre a teoria do desenvolvimento do capital, ou lei do valor-trabalho, de Marx, e perpassa as categorias marxianas fulcrais para o entendimento do sistema capitalista e sua dinâmica. Embora esclareça, citando o próprio Marx, tratar-se de um esquema abstrato, um instrumento metodológico para captar o que não está aparente na realidade imediata, as interconexões internas do desenvolvimento do capital. Insuficiente para possibilitar previsões sobre o mundo real, sequer com poder explicativo sobre as crises a ponto de dispensar a necessidade de colher empiricamente dados "da produção capitalista, da concorrência e do crédito". (p. 85) Esta permanente atenção em explicitar a distinção entre modelo e realidade fez com que Mattick interpretasse o pensamento de Marx sem qualquer conteúdo apologético.

Preocupado em observar o desenvolvimento do capitalismo enquanto um processo contínuo e regular, portanto fora de seus momentos de alterações intensas de expansão e contração, a interpretação mattickeana de Marx situa as crises como parte desta normalidade. Em tais momentos de regularidade, observa-se uma pequena taxa de acumulação que oculta "as múltiplas convulsões e lutas sociais que envolve." (p. 116) Assim, para Mattick, as crises capitalistas são

[...] o modo específico como se dá a acumulação de capital no quadro do
mercado concorrencial em que as inter-relações da produção capitalista como
um todo se impõem por si próprias, por via da crise. [...] sendo a auto-
expansão do capital, o factor determinante do desenvolvimento, a "lei do
valor" revela-se cada vez menos em termos de flutuações quotidianas de
preços no mercado; ela exige, sim, uma crise generalizada. [...] E é
justamente porque é preciso uma crise para restabelecer as proporções
necessárias à continuação da formação de capital que os vários elementos de
crise se acumulam em cada período de expansão sem serem detectados nem
combatidos. (p. 116-117).

Pela perspectiva marxiana, Mattick demonstra que as teorias que explicam as crises por fatores como subconsumo ou superprodução de mercadorias, estão restritas a descrever "o aspecto exterior dos mecanismos da crise capitalista" (p. 126), dado que as flutuações do poder de compra são determinadas pelo ciclo econômico, e não o inverso. $\mathrm{Na}$ verdade, esta contradição entre produção e consumo segundo Marx, frisa Mattick, apenas pode ser eliminada, temporariamente, pelo aumento da acumulação de capital.

Ao enxergar na teoria do valor de Marx do desenvolvimento capitalista, uma teoria que é ao mesmo tempo "uma teoria geral da acumulação e uma teoria especial da crise", Mattick afirma que ambas apenas podem ser analisadas conjuntamente. E, contra os que vislumbram um "catastrofismo" em Marx, ou a visão de que teria ele teorizado Em Debat: Rev. Dig., ISSNe 1980-3532, Florianópolis, n. 7, p. 70-75, jan-jun, 2012. 
sobre uma "crise final", Mattick expõe uma concepção que articula teoria/prática/crise/luta de classes/revolução:

Embora a lei geral da acumulação mostre os limites históricos do capitalismo, não é possível dizer quando é que esses limites serão atingidos [...] Mas, uma vez que o capitalismo é assediado por crises com um grau de destrutividade cada vez maior, as convulsões sociais suscitadas por qualquer delas poderão - com sorte - conduzir a acções sociais passíveis de por fim ao sistema capitalista. Com a ascensão do capitalismo, surgiu também uma nova classe de trabalhadores industriais. Se estes trabalhadores tomarem consciência da sua situação de classe e da obsolescência histórica do capitalismo, não é inconcebível que decidam abolir as suas próprias condições de exploração e de privação e derrubem o sistema capitalista por meios políticos. Isto não só não é inconcebível, como, em certa medida, ocorreu mesmo, expressando-se no aparecimento de um movimento operário anticapitalista. [...] Numa palavra, Marx não previa um colapso 'automático' ou 'econômico' do capitalismo. Só a força das acções revolucionárias poderia mostrar se uma situação de crise particular iria ser a 'crise final' do capitalismo. (p. 133-134).

O caráter altamente abstrato da análise marxiana do capital, não impediu que ela demonstrasse elevada capacidade de previsão. O desenvolvimento do capitalismo seguiu as grandes linhas previstas por Marx, que por isso nunca foi negado. O que existe, de acordo com Mattick, são outras explicações fornecidas para estas tendências. Keynes representa uma destas explicações, posto que aclara a tendência de produção do capital no "longo prazo" (as aspas são de Mattick) diferentemente de Marx, porém na descrição da "tendência em si mesma e das condições de crise observáveis" (p. 145), sua discrepância com Marx se resume à perspectiva e à terminologia empregada.

Ao longo dos capítulos de MK, Mattick apresenta-nos um Keynes defensor da teoria neoclássica, mas partidário do protecionismo sempre que os interesses britânicos estivessem em questão (p. 164-166); alguém que aceita as conclusões de Marx sem o afirmar e procura, em nome da conservação das relações de produção existentes, remediar as contradições identificadas "por intervenções conscientes no mecanismo de mercado" (p. 173).

Por outro lado, o Marx interpretado por Mattick, foi alguém que concebeu a teoria menos como fundamento lógico de ações políticas de seu tempo, e mais como ferramenta de identificação da tendência geral do desenvolvimento do capitalismo no exato momento de sua expansão internacional. Alguém cujas previsões políticas ainda não se realizaram, e que não imaginou que o próprio "marxismo" se transformaria em ideologia legitimadora do capitalismo de Estado, acelerador, pela via política, da concentração e centralização próprias da acumulação competitiva do capital.

Após aclarar o leitor que a economia mista é na verdade uma economia na qual o Estado intervém, sendo esse dirigismo estatal que a caracteriza e não a propriedade 
pública, Mattick esquadrinha a economia mista percorrendo a elucidação de sua dinâmica pela compreensão da relação entre moeda e capital; as contraditórias relações com a tecnologia, automação e cibernética; a imbricação com a geopolítica. Tal profundidade analítica vem entremeada com a exposição de contraposições de ultrapassagem do capitalismo tais como a importância dos ócios sem necessidades, a centralidade da ação política para resolver o grau de cibernetização, a eliminação do caráter capitalista do comércio. Para Mattick, uma economia mista próspera apenas se sustenta temporariamente ou enquanto transição entre o laissez-faire e o capitalismo de Estado (p. 245).

Por fim, o capitalismo de Estado como modelo de desenvolvimento econômico, o imperialismo como imperativo da expansão, as ambigüidades de Marx como senda para a social-democracia e o bolchevismo, a formação de uma nova classe capitalista além da burguesia, o papel do proletariado e as possibilidades de superação do capitalismo são temas que, por razões de espaço, apenas registramos para realçar o alcance da obra.

Produzida pela editora Antígona, esta bem cuidada edição de MK vem acompanhada de índice remissivo e nos brinda com um sofisticado posfácio, de autoria de Jorge Valadas, que proporciona ao leitor o conhecimento da trajetória biográfica e intelectual de Mattick.

Valadas nos informa que o filho de imigrados pobres da Pomerânia (região na costa sul do Mar Báltico que hoje pertence à Polônia), adere à Liga Espartaquista de Rosa Luxemburg em 1918, aos 14 anos, e participa ativamente na revolução alemã. Sempre na linha de frente das greves, combates insurrecionais de rua e levantes, liga-se ao KAPD ${ }^{3}$ em 1920, aos 16 anos. O refluxo da revolução, aliado ao crescimento do nacional-socialismo e da repressão às tendências mais radicalizadas, tornam muito difíceis as condições de militância, sobrevivência material e integridade física de Mattick. Em 1926, aos 22 anos, ele decide emigrar para os EUA.

Nos EUA, Mattick combinou o trabalho como operário metalúrgico, a militância junto ao IWW ${ }^{4}$, o estudo aprofundado, principalmente de Marx, e a produção teórica. Envolveu-se no movimento dos desempregados pós-crise de 1929, e, a partir de 1934,

\footnotetext{
${ }^{3}$ Sigla em alemão do Partido Comunista Operário da Alemanha, organização de caráter antiparlamentar e crítica do sindicalismo integrador.

${ }^{4}$ Sigla em inglês de Industrial Workers of the World (Trabalhadores Industriais do Mundo), sindicato internacionalista de orientação revolucionária fundado nos EUA em 1905 e existente até os dias de hoje com seções em alguns países. Seus militantes são denominados wobblies.
} 
seu trabalho de escritor coloca-o na condição de diretor de revistas teóricas das correntes comunistas antibolcheviques nos EUA até 1943. ${ }^{5}$ Durante a guerra fria, Mattick se vê obrigado a sair do meio industrial, retirando-se com sua mulher e filho para uma propriedade rural no extremo nordeste dos EUA (Vermont).

Apenas em fins dos anos 1960, Mattick será retirado de seu isolamento forçado em função do renovado interesse pelas concepções do comunismo antiautoritário. A partir de então, e até a sua morte em 1981, aos 77 anos, realizou palestras pela Europa e América relacionadas a temas como "história do movimento operário e da relação entre fascismo e crise capitalista" (p. 437).

Chegados a este ponto, surge uma explicação crível para ajudar a entender como uma obra tão importante permanece inédita para o leitor brasileiro após 42 anos.

Assim como uma materialidade revolucionária vivida estabelece na subjetividade de um trabalhador da Siemens (cujo único certificado é o de operário metalúrgico fornecido pelo centro de formação dessa empresa em Berlim em 1923), certos pressupostos que fazem com que pessoas participantes das grandes lutas anticapitalistas da segunda metade da década de 1960 e primeira metade da década de 1970 queiram debatê-los; uma materialidade sindicalista vivida estabelece na subjetividade de um trabalhador da Villares (com certificado de torneiro mecânico fornecido pelo Serviço Nacional de Aprendizagem Industrial - SENAI), certos pressupostos que fazem com que pessoas participantes de lutas pela inclusão democrática e pela integração social e econômica no capitalismo, no mesmo período mencionado, queiram transformá-lo em líder maior desse processo de integração.

Portanto, não se trata de conhecer falsos remédios que transitoriamente prolongam a saúde do capital, mas de encontrar novas medicações para que o capital possa se curar de algumas mazelas sem precisar morrer. E como, no Brasil, muita energia e iniciativas foram despendidas para o segundo caso, faz sentido pensar que as energias e recursos para o primeiro caso permanecem insuficientes para editar livros de leitura obrigatória, como este "Marx e Keynes" de Paul Mattick.

\footnotetext{
5 Sucessivamente: Internacional Council Correspondence (Correspondência Conselhista Internacional) de 1934 a 1937, Living Marxism (Marxismo Vivo) de 1938 a 1941, e New Essays (Novos Ensaios) de 1942 a 1943.
}

Em Debat: Rev. Dig., ISSNe 1980-3532, Florianópolis, n. 7, p. 70-75, jan-jun, 2012. 